\title{
Addressing the Impact and Unmet Needs of Nonadherence in Asthma and Chronic Obstructive Pulmonary Disease: Where Do We Go From Here?
}

\author{
Richard Dekhuijzen, MD, PhD ${ }^{a}$, Federico Lavorini, MD, PhD ${ }^{b}$, Omar S. Usmani, MBBS, PhD ${ }^{c}$, and \\ Job F.M. van Boven, PharmD, PhD ${ }^{\mathrm{d}, \mathrm{e}}$ Nijmegen and Groningen, The Netherlands; Florence, Italy; and London, United Kingdom
}

Nonadherence to treatment, and its associated health and economic burden, is particularly problematic in asthma and chronic obstructive pulmonary disease management because of heterogeneous patient populations and the need for an inhaled route of drug administration. Symptom variability, comorbidities, and device switching further add to suboptimal adherence rates. As opposed to controlled clinical trials, real-life studies show consistently low inhaler adherence in daily practice, yet exact adherence rates have long been affected by disagreement on standardized definitions. The recently developed Ascertaining Barriers to Compliance taxonomy helps to address adherence research disparities by identifying 3 phases of adherence (initiation, implementation [including correct inhaler technique], and discontinuation). This review considers

${ }^{\mathrm{a}}$ Department of Pulmonary Diseases, Radboud University Medical Center, Nijmegen, The Netherlands

${ }^{b}$ Department of Internal Medicine, Section of Immunoallergology, Respiratory Diseases and Cell Therapy, University of Florence, Florence, Italy

${ }^{c}$ National Heart and Lung Institute, Imperial College London and Royal Brompton Hospital, London, United Kingdom

${ }^{\mathrm{d}}$ Department of General Practice, Groningen Research Institute for Asthma and COPD, University Medical Center Groningen, University of Groningen, Groningen, The Netherlands

e Unit of Pharmacoepidemiology and Pharmacoeconomics, Department of Pharmacy, University of Groningen, Groningen, The Netherlands

Editorial assistance in the development of the manuscript was funded by Teva Pharmaceuticals Industries (Frazer, Pa). Teva Pharmaceuticals provided a single medical-accuracy review of the final draft of the manuscript. The authors were not compensated and retained full editorial control over the content of the article.

Conflicts of interest: R. Dekhuijzen has received grants and personal fees from Chiesi, AstraZeneca, Teva, Mundipharma, and Boehringer Ingelheim; grants from GlaxoSmithKline; and personal fees from Sandoz and Zambon. All are unrelated to the present work. F. Lavorini has received consultancy or lecture fees and travel support for attending meetings from the following pharmaceutical companies: AstraZeneca, Boheringer Ingelheim, Chiesi, Menarini International, and Teva. All are unrelated to the present article. O. S. Usmani has received grants and personal fees from AstraZeneca, Boehringer Ingelheim, and Chiesi; personal fees from Aerocrine, Napp, Mundipharma, Sandoz, Takeda, Zentiva, Cipla, Trudell Medical, and Pearl Therapeutics; and grants from GlaxoSmithKline, Prosonix, and Edmond Pharma. All are unrelated to the present work. J. F. M. van Boven has received travel support from the Respiratory Effectiveness Group and European COPD Coalition; consultancy fees from AstraZeneca; speaker fees from Menarini; and research support from AstraZeneca, GlaxoSmithKline, Boehringer Ingelheim, and Chiesi. All are unrelated to the present article.

Received for publication August 21, 2017; revised November 1, 2017; accepted for publication November 2, 2017.

Available online $\mathbf{\square}$

Corresponding author: Richard Dekhuijzen, MD, PhD, Department of Pulmonary Diseases (614), Radboud University Medical Center, PO Box 9101, 6500 HB Nijmegen, The Netherlands. E-mail: richard.dekhuijzen@ radboudumc.nl.

2213-2198

(C) 2017 American Academy of Allergy, Asthma \& Immunology

https://doi.org/10.1016/j.jaip.2017.11.027 the reasons for and impact of suboptimal adherence, together with summaries of key studies that demonstrate how improving adherence can reduce exacerbations, inhaled corticosteroid use (in cases of better inhaler technique), hospitalizations, and treatment costs. Strategies to help ensure optimal adherence are discussed, including the choice of a patient-tailored inhaler, patient empowerment, education and training, and the potential of electronic monitoring and digital technology. It is concluded that a combined effort from payers, health care professionals, and manufacturers could make a real difference to asthma and chronic obstructive pulmonary disease control, as well as to health care budgets. (c) 2017 American Academy of Allergy, Asthma \& Immunology (J Allergy Clin Immunol Pract 2017; :ロ-匹)

Key words: Asthma; Chronic obstructive pulmonary disease; Adherence; Clinical outcomes; Economic outcomes; Strategies; Devices; Electronic monitoring; Training

\section{INTRODUCTION}

Nonadherence to inhaled treatment regimens for asthma and chronic obstructive pulmonary disease (COPD) is well known as being endemic and a central issue in the quality and economics of ambulatory medical care and drug trials. Nonadherence for these conditions is reported to be higher than that for many other chronic diseases (70\%-80\% vs 50\%, respectively). ${ }^{1,2}$ Indeed, adherence is lower for asthma inhaler treatments than for antihypertensives, diabetes treatments, statins, proton pump inhibitors, and breast cancer treatments (Figure 1).

The lack of an agreed definition for adherence has previously hindered research into this important area, with few studies examining the epidemiology, causes, and consequences of poor adherence using standardized terminology. Adherence and compliance are often used interchangeably, but they are not exactly the same. The term noncompliance has paternalistic associations, suggesting a possibly deliberate lack of patient involvement in their medication, whereas nonadherence is less judgmental and is therefore generally the preferred term. ${ }^{4}$

The newly established Ascertaining Barriers to Compliance taxonomy was developed to address the standardization of terminology, helping to facilitate meaningful clinical discussion and aid research analysis. Asthma and COPD are chronic diseases that will particularly benefit from this initiative because of the additional challenges presented by inhaler technique and the difference in patient profiles between the 2 conditions that are likely to affect adherence behaviors (eg, age of onset, prognosis, etc). 
Abbreviations used

COPD- chronic obstructive pulmonary disease

DPI-dry-powder inhaler

pMDI-pressurized metered-dose inhaler

The Ascertaining Barriers to Compliance taxonomy identifies 3 phases of adherence. The first is initiation, which describes when a patient takes the first dose of their medication. This is followed by implementation, which relates to how well a patient's dosing behavior corresponds to the prescribed regimen from the first dose to the last dose, with inhaler technique of prime importance. The final phase is discontinuation, which marks the end of therapy, and is integral to the level of persistence, or time to discontinuation. ${ }^{5}$ In clinical practice, there may be more than 1 sequence of these phases because of reinitiation of treatment.

Assessment of adherence is complex. Adherence to inhaled treatment regimens is generally greater in classical randomized controlled trials than in real-world studies. ${ }^{6-8}$ The levels of adherence and inhaler technique competence seen in clinical trials are no doubt influenced by trial conditions (eg, restrictive inclusion criteria, short duration, health care professional support, etc) and close monitoring, which may fail to reflect real-world differences between devices. Conversely, the methodology of real-world studies means that poor disease control may be related to factors other than the inhalation device, which are not easily differentiated (eg, inclusion of smokers and patients with certain comorbid conditions who are generally excluded from clinical trials). ${ }^{6,9,10}$ Furthermore, observational studies rarely report initiation or persistence data, concentrating instead on implementation. ${ }^{5}$ This has serious implications for adherence research because up to $25 \%$ of patients fail to collect their first prescription. ${ }^{5}$ Differentiating between true discontinuation and possible suboptimal implementation is key to understanding nonadherence. ${ }^{5}$

Despite the advances in respiratory care that have been introduced over the last 50 years, suboptimal control still accounts for a large proportion of the costs incurred by asthma and COPD. It is therefore time to address the underlying problem of nonadherence and make better use of available resources. ${ }^{11}$

In this review, we aim to provide an overview of the causes and consequences of nonadherence, discuss successful adherenceenhancing interventions, and provide a set of recommendations to ultimately improve asthma and COPD control and lower related health care spending.

\section{CAUSES AND EFFECTS OF SUBOPTIMAL ADHERENCE}

Adherence to inhaled therapies is worse than with oral and injected therapies (asthma) and transdermal formulations (COPD). ${ }^{4}$ This is at least partly due to the perceived complexity of inhaler administration, as well as a possible lack of confidence in this route of drug delivery.

\section{Causes}

There are numerous causes of nonadherence with inhaler use, which can be broadly broken down into intentional and unintentional factors (Figure 2). ${ }^{12}$ Intentional factors include ambivalence to (or lack of confidence in) treatment, denial of diagnosis, embarrassment about using inhalers in social

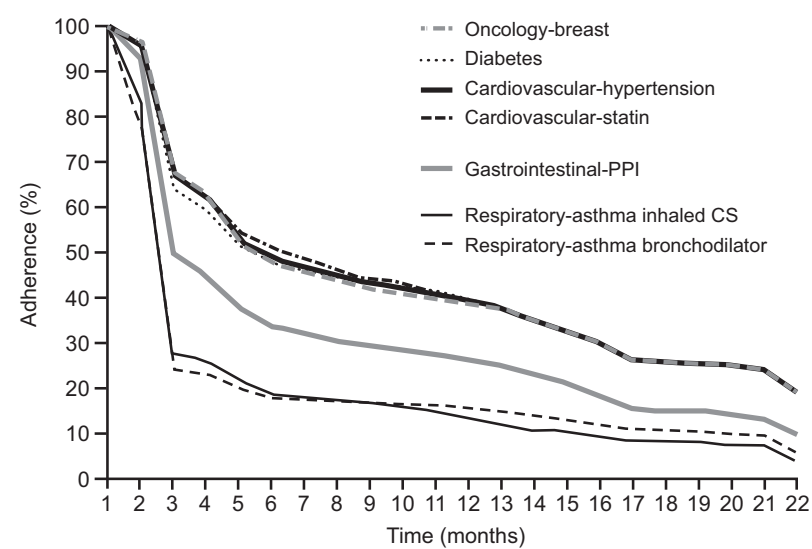

FIGURE 1. Adherence in chronic diseases. Patient adherence over time for various drug products (source of data: NDC Health). CS, Corticosteroid; $P P I$, proton pump inhibitor. Reprinted from Smith et $\mathrm{al}^{3}$ (Copyright 2010), with permission from Mary Ann Liebert, Inc. (permission conveyed through Copyright Clearance Center, Inc).

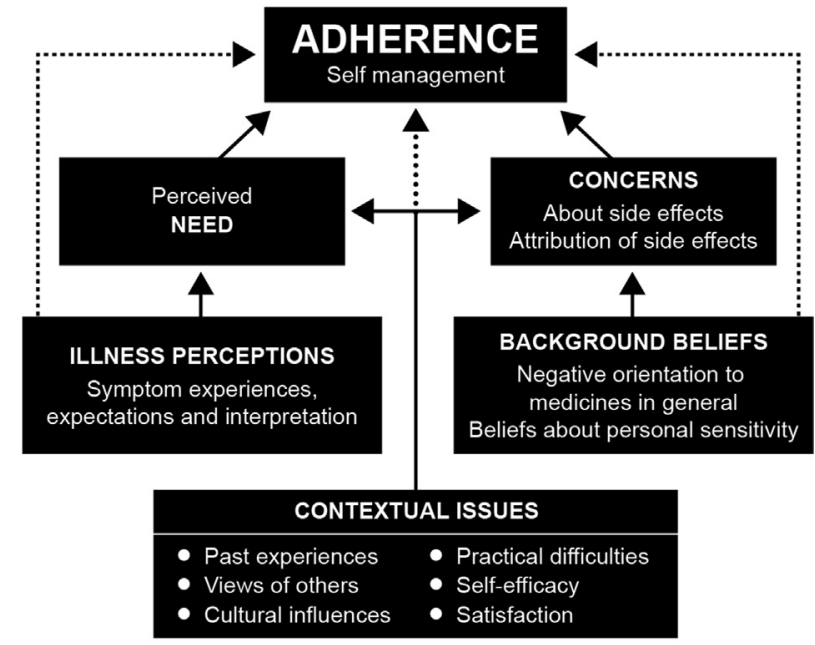

FIGURE 2. Multiple causes of nonadherence. Patient adherence to medication is influenced by a number of factors relating to how the individual judges the necessity of their treatment relative to their concerns. Reprinted from Horne ${ }^{12}$ (Copyright 2006), with permission from Elsevier.

situations, peer-group pressures (particularly applicable to adolescents), concern about adverse events, and erroneous beliefs that treatment can be stopped because symptoms have improved. $^{4,13,14}$

Unintentional factors include poor inhaler technique (even though the patient thinks he or she is using it correctly), incorrect inhaler use, lack of understanding about when to use an inhaler, forgetfulness, and language barriers. ${ }^{10,13}$ Other factors that can lead to unintentional nonadherence are the need for multiple devices and/or concomitant conditions requiring polypharmacy as well as a disruptive lifestyle, for example, frequent long-haul flights, shift work, and personal/family crises. ${ }^{4,14-16}$

An alternative 3-part classification of nonadherence was devised by the World Health Organization, ${ }^{1}$ which distinguishes 
TABLE I. Costs of poor inhalation technique for patients using budesonide/formoterol Turbohaler and fluticasone/salmeterol Accuhaler

\begin{tabular}{lrcr}
\hline & \multicolumn{3}{c}{ Costs $(€$, million) } \\
\cline { 2 - 4 } Resource use & Spain & Sweden & $\begin{array}{c}\text { United } \\
\text { Kingdom }\end{array}$ \\
\hline Hospitalization & 57.7 & 21.5 & 11.5 \\
Emergency department visits & 3.6 & 4.2 & 1.2 \\
Antimicrobial courses & 0.2 & 0.1 & 2.4 \\
Oral corticosteroids & 0.7 & 0.2 & 2.0 \\
Productive days lost & 93.0 & 194.3 & 389.6 \\
\hline
\end{tabular}

Adapted from Lewis et $\mathrm{al}^{29}$ (Copyright BioMed Central).

erratic nonadherence, meaning unintentional nonadherence due to sporadic forgetfulness (eg, caused by a busy lifestyle); intelligent nonadherence, which refers to intentional nonadherence as a result of a reasoned decision to reject therapy as described earlier; and unwitting nonadherence, which is a form of unintentional nonadherence, usually due to misunderstanding instructions or poor inhaler technique. ${ }^{17}$

Additional considerations for patients with COPD that may affect adherence include the fact that patients in this group are generally older than those with asthma (asthma can be diagnosed as early as 1 year of age vs a median age at diagnosis of 68 years for COPD) ${ }^{18-20}$ Older age is accompanied by the potential for lower cognitive function (up to $50 \%$ in some studies) and an associated possibility of misunderstanding treatment details, plus a greater probability of comorbidity/polypharmacy and the link to unintentional nonadherence. ${ }^{14}$ Poorer prognosis in such patients and greater risk of disease-associated depression may both contribute to adherence issues due to fatalism or apathy, while mobility and dexterity problems also play a part. In addition, patients with COPD often have limited ability to inhale with enough force to achieve adequate drug delivery from a drypowder inhaler (DPI). ${ }^{20}$

Several studies have explored the impact of suboptimal treatment on patient outcomes and health care resources including drug costs, hospitalizations, and loss of productivity.

\section{Effects: Clinical consequences}

A number of studies have consistently demonstrated suboptimal inhaler technique to be associated with poor clinical outcomes.

A United Kingdom (UK) retrospective analysis investigated the effect of poor pressurized metered-dose inhaler (pMDI) technique on outcomes in 3981 patients with asthma in 15 general practices during 2009. ${ }^{21}$ Patients with poor pMDI technique had higher risks of poor asthma control, as defined by the Global Initiative for Asthma strategy guidelines, ${ }^{22}$ and needed more systemic corticosteroid prescriptions than did those who operated their device correctly. Of the patients who had their inhaler technique tested using the asthma inhalation monitor machine, $58 \%, 52 \%$, and $38 \%$ failed to use the pMDI correctly during the first, second, and third tests, respectively. Incorrect inhaler use was significantly correlated with poor outcomes. Compared with patients using their inhaler correctly, almost 4 times as many patients failing the asthma inhalation monitor test had uncontrolled asthma and more than twice as many had partly controlled asthma $(P<.0001$ vs those who passed the first test for both levels of control). In addition, $68 \%$ of patients with 1 or more asthma exacerbations failed their first inhaler technique test $(P=.03)$, while $67 \%$ of those prescribed a short course of prednisolone in the previous 3 months also failed their initial test $(P<.05$ vs those who passed their first test $) .^{21}$

In a retrospective US study based on data from the SAPPHIRE (Study of Asthma Phenotypes and Pharmacogenomic Interactions by Race-Ethnicity) trial, $^{23}$ the relationship between low levels of adherence to inhaled corticosteroids and the incidence of asthma exacerbations was investigated. The authors conservatively estimated that $24 \%$ of asthma exacerbations could have been avoided with greater adherence to inhaled corticosteroids. They also suggested that although incremental improvements in adherence may be associated with a decreased risk of exacerbations, this relationship is nonlinear and that an adherence threshold of $75 \%$ of the prescribed dose is required to significantly reduce exacerbations (hazard ratio, 0.61; 95\% CI, 0.41-0.90 vs adherence $\leq 25 \%$ ).

In a cross-sectional, observational study in Italy, 1664 adolescent and adult patients (aged $>14$ years) with asthma or COPD were surveyed about inhaler-handling competence. ${ }^{24}$ Critical errors in device handling were significantly associated with increased risk of hospitalization $(P=.001)$, emergency department visits $(P<.001)$, use of antibiotics $(P<.001)$, and courses of oral corticosteroids $(P<.05)$. Similarly, a real-life assessment compared exacerbation rates in 2935 patients with COPD using 6 commonly prescribed inhalers in France. ${ }^{25}$ Inhalation technique was accurate in less than $40 \%$ of patients, irrespective of device. The rate of severe exacerbations over 3 months of treatment doubled in patients with at least 1 critical inhalation error compared with those with no errors $3.3 \%$ vs $6.9 \%$, respectively; $P<.05)$.

A systematic review of 12 studies in patients with COPD investigated the association between level of adherence and clinical and economic outcomes. ${ }^{26}$ Most studies were retrospective database studies. Seven studies focused on the impact of adherence on hospitalization, most of which showed either increased admissions with poor adherence or decreased admissions for patients who adhered to their prescribed treatment.

\section{Effects: Economic consequences}

In both asthma and COPD, poor clinical outcomes have been shown to translate into increased direct and indirect costs.

The total cost of asthma currently comprises up to $2 \%$ of health care budgets. ${ }^{1}$ Treatment costs are 3.5 times higher in patients experiencing acute asthma exacerbations than in patients not experiencing exacerbations. ${ }^{27}$ Similarly, in patients with COPD, exacerbations are thought to be responsible for $35 \%$ to $45 \%$ of all health care costs related to the disease. ${ }^{28}$

Two studies in patients with asthma or COPD quantified the economic cost of inhaler misuse: one of them was conducted across 3 European countries (the United Kingdom, Spain, and Sweden $)^{29}$ and the other was based in the United States. ${ }^{30}$ The European study used a burden-of-illness economic model to measure the impact of inhaler misuse over 1 year in patients using the 2 most commonly prescribed dry-powder devices-budesonide/formoterol Turbohaler and fluticasone/salmeterol Accuhaler. The total cost incurred (on the basis of 2015 prices), including costs for hospitalizations, emergency department visits, antimicrobial courses, oral corticosteroid courses, and productive days 
TABLE II. Examples of clinical and economic impact of adherence in asthma and COPD

\begin{tabular}{|c|c|c|}
\hline Study & Study details & Outcomes \\
\hline \multicolumn{3}{|l|}{ Asthma } \\
\hline $\begin{array}{l}\text { Morton et } \mathrm{al}^{32} \\
\quad \text { (UK STAAR study) }\end{array}$ & $\begin{array}{l}\text { Use of EMD over } 1 \mathrm{y} \text { in } 77 \text { children (aged 6-16 y) } \\
\text { with poorly controlled asthma 1:1 } \\
\text { randomization, in which one group (A) had } \\
\text { alarms and 3-monthly reviews, and the control } \\
\text { group (B) had no alarms or reviews }\end{array}$ & $\begin{array}{l}\text { Clinical } \\
\text { Asthma control (as measured by the ACQ score) } \\
\text { significantly improved in both groups } \\
\text { over } 12 \text { mo. } \\
\text { Adherence was significantly greater in group A } \\
\text { ( } 70 \% \text { vs } 49 \% \text { in group B; } P \leq .001 \text { ) over the } \\
\text { study period. } \\
\text { GP/ED visits, days off school because of asthma, } \\
\text { requirement for courses of oral steroids, and } \\
\text { hospital admissions were all lower in group A } \\
\text { than in group B, significantly so for steroids } \\
(P=.008) \text { and admissions ( } 5 \text { times lower; } \\
P<.001) \text {. } \\
\text { Economic } \\
\text { There would appear to be cost savings using this } \\
\text { approach despite outlay for EMD. }\end{array}$ \\
\hline $\begin{array}{l}\text { Price et } \mathrm{al}^{33} \\
\quad \text { (United States) }\end{array}$ & $\begin{array}{l}\text { Prospective, real-world, cross-sectional survey of } \\
243 \text { US adult patients with asthma ( } 41 \% \text { of } \\
\text { whom had poorly controlled asthma) and their } \\
\text { physicians; questionnaires included DSP, ACT, } \\
\text { EQ-5D-3L, JSEQ, and MMAS-8 }\end{array}$ & $\begin{array}{l}\text { Clinical } \\
24 \% \text { of patients showed high adherence, } 37 \% \\
\text { medium/moderate adherence, and } 40 \% \text { low } \\
\text { adherence. } \\
\text { Improvements in asthma control, quality of sleep, } \\
\text { overall health status, and frequency of } \\
\text { exacerbations were significantly associated } \\
\text { with greater patient device satisfaction } \\
(P=.002) \text { and higher adherence }(P=.049) \text {. }\end{array}$ \\
\hline $\begin{array}{l}\text { Zafari et } \mathrm{al}^{34} \\
\quad \text { (United States) }\end{array}$ & $\begin{array}{l}\text { Markov model of asthma to simulate impact of full } \\
\text { adherence on asthma control, exacerbations, } \\
\text { health care costs, and QALYs over a 10-y } \\
\text { period in patients who had uncontrolled asthma } \\
\text { at the current level of adherence (status quo) }\end{array}$ & $\begin{array}{l}\text { Clinical } \\
\text { Compared with the status quo, ensuring full } \\
\text { adherence reduced the number of weeks with } \\
\text { uncontrolled asthma by } 31 \% \text { and the rate of } \\
\text { exacerbations by } 40 \% \text {. } \\
\text { Economic } \\
\text { The status quo level of control was associated } \\
\text { with a cost of US } \$ 2,786 \text { and } 7.55 \text { QALYs over } \\
10 \text { y compared with US } \$ 5,973 \text { and } 7.68 \\
\text { QALYs for full adherence, representing an } \\
\text { incremental cost-effectiveness ratio of } \\
\text { US } \$ 24,515 / \text { QALY gained (all costs were } \\
\text { adjusted to } 2011 \text { US } \$ \text { ). } \\
\text { Taking loss of productivity into account, the } \\
\text { model showed that full adherence would be } \\
\text { cost-effective and associated with a significant } \\
\text { return on investment. }\end{array}$ \\
\hline \multicolumn{3}{|l|}{ COPD } \\
\hline $\begin{array}{l}\text { Belleudi et } \mathrm{al}^{2} \\
\quad \text { (Italy) }\end{array}$ & $\begin{array}{l}\text { Population-based cohort study in } 12,124 \text { patients } \\
\text { aged } \geq 45 \text { y who were discharged after a COPD } \\
\text { exacerbation in } 3 \text { Italian regions; health } \\
\text { care-linked data sets (for hospitalization, } \\
\text { mortality, and drugs) were used to assess the } \\
\text { impact of adherence on 5-y survival }\end{array}$ & $\begin{array}{l}\text { Clinical } \\
\text { After a mean follow-up of } 2.4 \mathrm{y} \text {, the mortality rate } \\
\text { was lower in all treatment categories when } \\
\text { medication was taken regularly rather than } \\
\text { occasionally: } \\
\text { LABA/ICS: } 8.2 \% \text { vs } 11.3 \% \text { ( } 280 \text { preventable } \\
\text { deaths vs regular LABA/ICS use) } \\
\text { LABA: } 9.7 \% \text { vs } 12.7 \% \text { ( } 39 \text { and } 90 \text { preventable } \\
\text { deaths, respectively, vs regular LABA/ICS use) }\end{array}$ \\
\hline $\begin{array}{l}\text { Chrystyn et } \mathrm{al}^{35} \\
\quad \text { (international) }\end{array}$ & $\begin{array}{l}\text { Large, multinational, cross-sectional, real-world } \\
\text { survey of } 1443 \text { patients using the DSP } \\
\text { questionnaire to examine the relationship } \\
\text { between inhaler satisfaction, adherence, and } \\
\text { health status }\end{array}$ & $\begin{array}{l}\text { Clinical } \\
\text { The higher the level of adherence, the lower the } \\
\text { number of total exacerbations and } \\
\text { hospitalizations due to exacerbations in the } \\
\text { previous } 12 \text { mo }(P<.001 \text { for both). } \\
\text { Higher adherence was also associated with better } \\
\text { quality of life and sleep patterns } \\
\text { (both } P<.0001) \text {. }\end{array}$ \\
\hline
\end{tabular}


TABLE II. (Continued)

\begin{tabular}{|c|c|c|}
\hline Study & Study details & Outcomes \\
\hline $\begin{array}{l}\text { van Boven et al }{ }^{36} \\
\text { (The Netherlands) }\end{array}$ & $\begin{array}{l}\text { Evaluation of the cost-effectiveness of } \\
\text { PHARMACOP, the 3-mo intervention based in } \\
170 \text { Belgian community pharmacies that } \\
\text { significantly improved adherence and inhaler } \\
\text { technique }\end{array}$ & $\begin{array}{l}\text { Economic } \\
\text { The PHARMACOP intervention was associated } \\
\text { with a cost saving of } € 227 / \text { patient within } 1 \text { y } \\
\text { and a significant decrease in exacerbation- } \\
\text { related hospitalizations. } \\
\text { The initial increase in PHARMACOP-related } \\
\text { costs }(€ 161 / \text { patient) was offset by savings of } \\
€ 388 / \text { patient for exacerbation-related expenses. } \\
\text { All costs were expressed in } 2013 € \text {. }\end{array}$ \\
\hline $\begin{array}{l}\text { Toy et } \mathrm{al}^{37} \\
\text { (United States) }\end{array}$ & $\begin{array}{l}\text { Retrospective study using a large administrative } \\
\text { claims database covering } 8 \text { million insured lives } \\
\text { over a } 7 \text {-y period }\end{array}$ & $\begin{array}{l}\text { Economic } \\
\text { Using a multivariate regression model, higher } \\
\text { adherence was found to be correlated with } \\
\text { reduced annual number of inpatient days, } \\
\text { inpatient visits, and ED visits. } \\
\text { On the basis of } 1000 \text { patients, a } 5 \% \text { increase in } \\
\text { adherence would lead to an average reduction } \\
\text { of } 2.5 \% \text { in inpatient visits. } \\
\text { This translates into an estimated cost decrease of } \\
\text { US } \$ 296,598 \text { for inpatient visits and US } \$ 7,410 \\
\text { for ED visits. Taking into account a slight } \\
\text { increase in outpatient costs, the net annual } \\
\text { saving would be US } \$ 300,789 \text {. } \\
\text { All costs from the survey were adjusted to } \\
2008 \text { US } \$ \text {. }\end{array}$ \\
\hline $\begin{array}{l}\text { Vestbo et } \mathrm{al}^{38} \\
\quad \text { (UK TORCH study) }\end{array}$ & $\begin{array}{l}\text { Observational adherence study within TORCH, a } \\
\text { 3-y, multicenter, randomized, double-blind, } \\
\text { parallel-group, placebo-controlled study. } \\
\text { TORCH compared salmeterol, fluticasone } \\
\text { propionate, a combination of these drugs, and } \\
\text { placebo in } 6112 \text { patients with moderate to } \\
\text { severe COPD }\end{array}$ & $\begin{array}{l}\text { Clinical } \\
\text { A strong association was found between } \\
\text { adherence and mortality and risk of } \\
\text { hospitalization due to exacerbations. } \\
\text { In a multivariate Cox model, good adherence } \\
(\geq 80 \% \text { use of study medication) was associated } \\
\text { with a } 60 \% \text { decreased risk of death at any time } \\
\text { in the 3-y study period and a decreased rate of } \\
\text { severe exacerbations of } 44 \% \text { (both } P=.001 \text { ), } \\
\text { independent of study treatment. }\end{array}$ \\
\hline
\end{tabular}

$A C Q$, Asthma Control Questionnaire; $A C T$, asthma control test; $D S P$, Adelphi Disease-Specific Programme; $E D$, emergency department; $E M D$, electronic monitoring device; $E Q-5 D-3 L$, three-level EuroQol five-dimensional questionnaire; GP, general practitioner; ICS, inhaled corticosteroid; JSEQ, Jenkins Sleep Evaluation Questionnaire; $L A B A$, long-acting $\beta_{2}$-agonist; MMAS-8, 8-item Morisky Medication Adherence Scale; PHARMACOP, PHARMAceutical Care for COPD; QALY, quality-adjusted life-year; STAAR, STudy of Asthma Adherence Reminders; TORCH, Towards a Revolution in COPD Health.

lost, ranged from $€ 155.2$ million (Spain) and $€ 220.3$ million (Sweden) to $€ 406.7$ million (United Kingdom). ${ }^{29}$ A breakdown of these data is presented in Table I. In the US study, an annual expenditure on inhalers of US $\$ 25$ billion was assumed; taking the level of inhaler misuse to be $28 \%$ to $68 \%$, an estimated US $\$ 7$ to $\$ 17$ billion was being wasted each year. ${ }^{30}$

In the previously discussed systematic review in patients with COPD, 3 studies assessed costs associated with hospitalizations due to poor adherence. ${ }^{26}$ All reported increased medication costs but decreased costs for inpatient care and COPD-related treatment in patients who adhered to their treatment regimen.

\section{THE IMPACT OF IMPROVING ADHERENCE: A "TREATABLE TRAIT"}

There is compelling study evidence showing the positive impact that improved adherence has on clinical and economic outcomes. In a 2015 systematic review of 23 studies, 4 goodquality studies in adult patients with asthma showed that a $25 \%$ increase in adherence was associated with approximately a $10 \%$ reduction in severe exacerbations. ${ }^{31}$ This finding has been substantiated in a number of studies in asthma and COPD. A summary of the findings from key studies is presented in Table II.

\section{THE IMPORTANCE OF TAILORING THE INHALER TO THE PATIENT}

There are more than 200 drug-inhaler device combinations (branded and generic) available, ${ }^{39}$ and choosing the right device for the individual patient is crucial to ensuring correct technique and improving the likelihood of good adherence to therapy. ${ }^{40}$ Devices vary widely with regard to technique, patient suitability, and patient preference, which makes the role of the prescriber in selecting the optimal device potentially fraught and overwhelming. The situation can be further complicated by patients being switched between inhalers for therapeutic reasons, health insurance policies, or prescribing practices. Bioequivalent versions of inhaled formulations may be delivered using different devices, thus causing confusion to the patient and the potential for adherence problems, either intentional or unintentional. ${ }^{41}$ There is therefore a strong case for maintaining patients on their initial device, as any switch-related savings may be offset by 
TABLE III. Factors affecting choice of inhaler device

\begin{tabular}{|c|c|c|c|c|}
\hline \multirow[b]{2}{*}{ Device type } & \multicolumn{2}{|c|}{ Sufficient inspiratory flow* } & \multicolumn{2}{|c|}{ Insufficient inspiratory flow } \\
\hline & $\begin{array}{c}\text { Good } \\
\text { coordination }\end{array}$ & $\begin{array}{c}\text { Poor } \\
\text { coordination }\end{array}$ & $\begin{array}{c}\text { Good } \\
\text { coordination }\end{array}$ & $\begin{array}{c}\text { Poor } \\
\text { coordination }\end{array}$ \\
\hline pMDI alone & レ & $x$ & $\boldsymbol{}$ & $x$ \\
\hline pMDI + spacer & レ & レ & レ & レ \\
\hline DPI & レ & レ & $x$ & $x$ \\
\hline BAI & $レ$ & $\nu$ & $\nu$ & $\nu$ \\
\hline Soft-mist inhaler & $レ$ & $\dagger$ & $\nu$ & $\dagger$ \\
\hline Nebulizer & $\boldsymbol{V}$ & 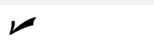 & レ & $\swarrow$ \\
\hline
\end{tabular}

$B A I$, Breath-actuated inhaler.

Adapted from Dekhuijzen et al. ${ }^{44}$

*Able to produce at least $30 \mathrm{~L} / \mathrm{min}$.

$\dagger$ May need some level of coordination.

reduced adherence, compromised control, and worse outcomes. ${ }^{42}$ Any change in device that is deemed necessary must be supported by thorough training in technique and comprehensive patient education. ${ }^{10}$

It makes sense, therefore, to carefully explore a patient's concerns and capabilities before selecting the most appropriate device. The patient's physical and mental abilities are key factors when deciding which device is most appropriate. Coordination competence is important for pMDIs and breath-actuated devices because failure to actuate efficiently can lead to drug deposition in the oropharynx rather than in the lungs. ${ }^{10}$ Inhaler technique declines over time in most patients, so it is prudent to monitor technique periodically and provide educational interventions as required. This is especially pertinent for elderly patients in cognitive decline because they may experience problems in remembering inhaler technique, may have dexterity issues that compromise delivery, and are likely to have comorbid conditions and receive multiple therapies. Given that we have yet to see sustained improvements in patients' ability to use inhalers correctly, ${ }^{43}$ prescribing simple devices and combined formulations when possible is desirable to encourage good adherence from the outset.

An important physical aspect of inhaler use involves the inspiratory flow level of the patient because this can exclude some device options, as presented in Table III. ${ }^{44}$ Although DPIs theoretically avoid coordination issues by being solely driven by inspiratory flow, this benefit is overridden if the patient has suboptimal capacity to activate drug delivery. A general rule is that a pMDI is suited to a patient who tends to use slow, deep inhalations, whereas an ideal candidate for a DPI is one who can easily perform a rapid, deep, and prolonged inspiration. ${ }^{45}$

Patient satisfaction is vital to adherence because patients who are confident in taking their medication are more likely to persevere with treatment. ${ }^{33}$ Real-world studies in both COPD and asthma have shown a significant correlation between device satisfaction, adherence, and outcomes. ${ }^{35,46}$ A patient's support network is also crucial, particularly in the case of vulnerable patients. Exploring a patient's understanding of the efficacy and tolerability of their medication may highlight the need for an indepth discussion before device selection to manage expectations and optimize treatment satisfaction.

A real-world COPD study reported that the main inhaler characteristics influencing satisfaction were as follows: having a robust construction that would not break easily; being easy to hold and carry; and having simple, easy-to-follow instructions. ${ }^{35}$ In a
TABLE IV. Matching adherence strategies to the type of nonadherence as defined by the World Health Organization

\begin{tabular}{|c|c|}
\hline Type of nonadherence & Intervention \\
\hline $\begin{array}{l}\text { Erratic (unintentional } \\
\text { nonadherence due to sporadic } \\
\text { forgetfulness, eg, because of a } \\
\text { busy lifestyle) }\end{array}$ & $\begin{array}{l}\text { Simplify and tailor regimen (eg, } \\
\text { align time[s] of intake with } \\
\text { other drugs that are used, if } \\
\text { possible) } \\
\text { Implement behavioral strategies } \\
\text { such as linking with daily } \\
\text { habits (eg, storing inhaler next } \\
\text { to toothbrush) and sending } \\
\text { reminders (eg, by smartphone) } \\
\text { Self-monitoring with support } \\
\text { from others (eg, family } \\
\text { members) }\end{array}$ \\
\hline $\begin{array}{l}\text { Intelligent (intentional } \\
\text { nonadherence as a result of a } \\
\text { reasoned decision to reject } \\
\text { therapy) }\end{array}$ & $\begin{array}{l}\text { Patient education and counseling } \\
\text { (eg, discuss mechanism of } \\
\text { action and ways to minimize } \\
\text { risk for side effects) } \\
\text { Negotiate therapy/shared decision } \\
\text { making (eg, in choosing the } \\
\text { inhaler) } \\
\text { Motivational interviewing (eg, } \\
\text { enhance patients' intrinsic } \\
\text { motivation by emphatic } \\
\text { consultations with open } \\
\text { questions and respect for } \\
\text { autonomy) } \\
\text { Link therapy with personal goals } \\
\text { (eg, reduction in number of } \\
\text { annual exacerbations) } \\
\text { Reimbursement of therapy (if } \\
\text { financial reason) }\end{array}$ \\
\hline $\begin{array}{l}\text { Unwitting (unintentional } \\
\text { nonadherence, usually due to } \\
\text { misunderstanding instructions } \\
\text { or poor inhaler technique) }\end{array}$ & $\begin{array}{l}\text { Written or visual self- } \\
\text { management plans } \\
\text { Patient education in inhaler } \\
\text { technique by doctor, nurse, or } \\
\text { pharmacist (reinforced } \\
\text { periodically) } \\
\text { Change inhaler if persistent } \\
\text { misuse or inability to use } \\
\text { current inhaler } \\
\text { Audiovisual materials (eg, } \\
\text { smartphone apps) }\end{array}$ \\
\hline
\end{tabular}

Reproduced from Lareau and Yawn ${ }^{15}$ (Copyright 2010), with permission from Dove Medical Press Ltd (permission conveyed through Copyright Clearance Center, Inc).

real-world asthma study, the patient's level of satisfaction with their device was associated with improvements in quality of life, sleep, exacerbation frequency, and health care professional visits; the 3 most important satisfaction-related features were the same as in the COPD study. ${ }^{46}$ Although patient choice is central to health care policy, it is important for health care professionals to offer only those devices that are suitable for the patient's capability.

Current asthma and COPD treatment guidelines lack clear and specific guidance on the choice of inhalation device, perhaps assuming that clinicians have all the information they need about inhaler characteristics and operation.9,45 This situation needs to be addressed, given the confusing array of available devices and physician time constraints; clear direction is required on how to select the most appropriate inhaler for individual patients. 


\section{STRATEGIES TO IMPROVE INHALER ADHERENCE IN CLINICAL PRACTICE}

As discussed, nonadherence manifests itself in 3 patterns, all requiring patient-tailored solutions, as presented in Table IV. ${ }^{15,47}$

The need for a coordinated approach to suboptimal adherence has been addressed by the First European Congress on Adherence to Therapy, resulting in a European charter. ${ }^{48}$ This charter acknowledges adherence to treatment as a right for patients with chronic disease and gives comprehensive advice on how to improve adherence by targeting patients and their families/caregivers, health care professionals, manufacturers, guideline creators, and research institutions. ${ }^{48}$

Several adherence-enhancing intervention strategies warrant further attention, including stimulating patient empowerment, education and training, and use of electronic monitoring and devices. These strategies are discussed in more detail herein.

\section{Patient empowerment}

A multifactorial approach to addressing nonadherence has proven effective, as demonstrated in a randomized controlled trial over 12 months in 146 Spanish patients with COPD. ${ }^{49}$ Patients were randomized to either a control group or an intervention group that received motivational interviews to explore beliefs and attitudes plus written and audiovisual materials covering disease information and training in inhaler technique. At the end of the study, the intervention group achieved a $79.5 \%$ adherence rate compared with $49 \%$ in the control group $(P=.002)$.

As a consequence of successful outcomes such as this, motivational interviewing is being increasingly used as a stepwise tool to empower patients over time. This can help them overcome apathy, ambivalence, and poor levels of motivation that can perpetuate poor adherence to medication, frequent exacerbations, and compromised quality of life. Note that this strategy is deemed particularly helpful to tackle intentional nonadherence.

A second study in 734 patients with COPD investigated the effectiveness of the 3-month PHARMACOP (PHARMAceutical Care for COPD) intervention in improving adherence in patients registered with 170 community pharmacies in Belgium. ${ }^{50}$ One group of patients received standard pharmacist care and a second group received 2 one-to-one counseling sessions, the first at initiation and the second at the 1-month follow-up visit. The sessions were tailored to each patient and included education, inhaler technique, and addressing behavioral issues. At 3 months, inhalation technique had significantly improved in the intervention group compared with the control group, with a mean estimated difference of $13.5 \%$ in percentage of correct inhalation steps $(P<.0001)$. The intervention corrected almost all major technique errors. Notably, the annual hospitalization rate was significantly lower in the intervention group compared with the control group $(P=.003)$.

\section{Education and training}

Most patients requiring inhaler therapy are managed at the community level, which puts primary care health professionals in a key position to reach the greatest number of patients with adherence-improving initiatives. As can be seen from the PHARMACOP study, pharmacist involvement in adherence strategies is very effective. ${ }^{50}$ Their accessibility, respect, and knowledge make them ideally placed to counsel patients about their inhaler therapy at all stages of the adherence pathway_initiation (setting expectations at first prescription), implementation (device training; identifying over-/under-usage through drug records), and discontinuation (using medicine-use reviews to assess persistence) although their exact role may vary by country and setting. ${ }^{51}$

Ensuring that health care professionals are familiar with inhaler techniques is key to any such program and it is therefore of concern that $39 \%$ to $85 \%$ of doctors, nurses, and respiratory therapists have limited expertise in the proper use of marketed devices. ${ }^{10,30,52,53}$ Practical training tools are available to help health care professionals understand how to use an inhalation device properly so they can pass on this knowledge to their patients. Even though this can be a challenge given the time constraints in general practice, the clinical and economic benefits are potentially worth the commitment. ${ }^{9,32,34,36}$

An open, empathetic approach to consultations encourages patients to be honest about their concerns and beliefs so that these can be addressed before they become detrimental to disease control. ${ }^{51}$ A well-established approach is to ask the patient to repeat what they have understood from the consultation, thus ensuring that the patient does not leave having misunderstood important information. ${ }^{51}$ Tackling the subject of adherence with a patient can be a sensitive subject because it is easy for patients to inadvertently feel like they are being judged or reprimanded, potentially making their answers unreliable. One suggestion is to use neutral language to initiate discussion, such as "Lots of people don't take their inhalers as prescribed." ${ }^{\text {I1 }}$ Also, asking about day-to-day management at home and practicing nonverbal attentiveness, such as head nodding and eye-to-eye contact, can facilitate openness. ${ }^{51}$

An important finding in adherence studies is that adherence is improved by sharing decision making with the patient. ${ }^{13,51,54}$ When the patient is involved in their own care, they feel empowered and are more likely to learn about their condition, understand the importance of taking their doses correctly, and endeavor to do so. That said, this approach is more appropriate for patients who are willing and able to participate, taking into consideration age (younger rather than older patients), education (more rather than less educated), and current level of adherence (worse rather than better)..$^{51}$

Of course, the issue of cost-effectiveness is of prime importance in these times of severe budgetary restrictions. However, focusing on subsets of patients most likely to benefit from improved adherence has the potential to prove cost-effective across both asthma and COPD. These subgroups are patients of working age, those with polypharmacy, those with exacerbations, and those with uncontrolled disease. ${ }^{51}$

In general, the adherence strategies on which to focus are those that improve clinician-patient communication skills, use adherence counseling, include adherence information feedback (but of course only if it is viewed and acted on by the clinician), or involve electronic dose monitoring. ${ }^{51}$

\section{Use of electronic monitoring and digital technology}

Electronic dose monitoring has been shown to have a positive impact on adherence in both asthma and COPD and is rising in popularity because of its precision and objectiveness. ${ }^{4,32,55}$ The cost benefits of electronic monitoring remain unclear, but it has the potential to improve asthma control through more efficient disease management. ${ }^{56}$ The STAAR (STudy of Asthma Adherence Reminders) study suggested a potential for savings despite 
the initial outlay, and of course the greater the uptake of a technology, the more rapidly product costs will decrease. ${ }^{17,32}$

The value of the objectiveness of electronic dose monitoring has been shown in a prospective observational study. In this study, 204 patients with COPD were discharged from hospital with an electronic audio-recording device attached to their preventer inhaler and then followed for 1 month. ${ }^{57}$ Data collected included quantity and quality of inhaler use, (reason for) hospital admissions, disease severity, and personal factors (eg, cognitive function), allowing measurement of both intentional and unintentional nonadherence. The adherence patterns identified helped inform clinicians as to which strategies would be likely to improve adherence. The mean actual adherence rate (a combination of intentional and unintentional nonadherence) over the study period was $22.9 \%$ of what would be expected if all doses had been taken correctly; most patients made errors in both inhaler use and technique.

A second cross-sectional, multicenter study in 1009 patients used the objectiveness of electronic monitoring to validate the 12-item Test of Adherence to Inhalers, a questionnaire used in asthma and COPD. The group using electronic monitoring was compared with the self-report group to allow validation of the new tool to easily identify nonadherence in patients and help classify barriers to effective inhaler use. ${ }^{58}$ Results showed that in addition to adequate classification of adherence, the Test of Adherence to Inhalers instrument determined the predominant pattern of nonadherence in individual patients. ${ }^{58}$

Digital technology is also advancing rapidly in the field of telehealth, where platforms such as text messaging, telephonebased advisory services, follow-up/feedback via Internet, smartphone apps, and Bluetooth technology are becoming increasingly sophisticated and make an important contribution to the tools available to the clinician and patient. 9,59,60

\section{Recommendations}

Although the advances in respiratory medicine have theoretically improved outcomes for patients with asthma or COPD, these will continue to be compromised by poor adherence. It has been clearly shown in numerous clinical and real-world studies that improving adherence ultimately improves clinical and economic outcomes. It is therefore crucial to health care budgets and patient well-being that such interventions are implemented to address the issue of nonadherence.

The potential for objective monitoring has never been greater, and unless payers incorporate such adherence strategies into their asthma and COPD management policies, a key opportunity will continue to be missed. Electronic monitoring is a valuable option for the objective assessment of adherence and inhaler technique; after the initial financial outlay, long-term savings can be achieved. Combining this with other educational approaches, such as motivational interviewing and patient education, would be effective in reducing the cost of respiratory care. This would of course involve longer consultation times than currently allowed, but again, the cost of this would be offset by improved control and associated economic benefits.

Manufacturers can also play their part by incorporating electronic monitoring devices into their inhalers, which would mean an initial price increase, but the laws of economy of scale would eventually bring costs down and savings would rise. Manufacturers should also endeavor to make their inhalers as simple and intuitive to use as possible, ideally using visual or auditory signals when the correct technique has been achieved.

Involving patients in their own treatment has been shown to have a beneficial effect on adherence. This can be achieved using relatively low-cost initiatives, including educational materials and the input of community pharmacists - an often-underused resource.

\section{CONCLUSIONS}

Improving adherence-and hence improving clinical outcomes and reducing costs - in asthma and COPD appears to be eminently achievable with the implementation of appropriate strategies.

\section{Acknowledgments}

We thank Jackie Mayne of Anthemis Consulting Ltd for editorial assistance.

\section{REFERENCES}

1. World Health Organization. Adherence to long-term therapies: evidence for action. Geneva, Switzerland: World Health Organization; 2003.

2. Belleudi V, Di Martino M, Cascini S, Kirchmayer U, Pistelli R, Formoso G, et al. The impact of adherence to inhaled drugs on 5-year survival in COPD patients: a time dependent approach. Pharmacoepidemiol Drug Saf 2016;25: 1295-304.

3. Smith IJ, Bell J, Bowman N, Everard M, Stein S, Weers JG. Inhaler devices: What remains to be done? J Aerosol Med Pulm Drug Deliv 2010;23(Suppl 2): S25-37.

4. Makela MJ, Backer V, Hedegaard M, Larsson K. Adherence to inhaled therapies, health outcomes and costs in patients with asthma and COPD. Respir Med 2013; 107:1481-90

5. Vrijens B, Dima AL, Van Ganse E, van Boven JF, Eakin MN, Foster JM, et al. What we mean when we talk about adherence in respiratory medicine. J Allergy Clin Immunol Pract 2016;4:802-12.

6. Price D, Brusselle G, Roche N, Freeman D, Chisholm A. Real-world research and its importance in respiratory medicine. Breathe (Sheff) 2015;11:26-38.

7. Busse WW, O'Byrne PM, Bleecker ER, Lötvall J, Woodcock A, Andersen L, et al. Safety and tolerability of the novel inhaled corticosteroid fluticasone furoate in combination with the $\beta_{2}$ agonist vilanterol administered once daily for 52 weeks in patients $\geq 12$ years old with asthma: a randomised trial. Thorax 2013;68:513-20.

8. Sadatsafavi M, Lynd L, Marra C, Bedouch P, Fitzgerald M. Comparative outcomes of leukotriene receptor antagonists and long-acting $\beta$-agonists as add-on therapy in asthmatic patients: a population-based study. J Allergy Clin Immunol 2013;132:63-9.

9. Dekhuijzen PN, Bjermer L, Lavorini F, Ninane V, Molimard M, Haughney J. Guidance on handheld inhalers in asthma and COPD guidelines. Respir Med 2014;108:694-700.

10. Braido F, Chrystyn H, Baiardini I, Bosnic-Anticevich S, van der Molen T, Dandurand RJ, et al. "Trying, but failing"- the role of inhaler technique and mode of delivery in respiratory medication adherence. J Allergy Clin Immunol Pract 2016;4:823-32.

11. Lavorini F, Fontana GA, Usmani OS. New inhaler devices - the good, the bad and the ugly. Respiration 2014;88:3-15.

12. Horne R. Compliance, adherence, and concordance: implications for asthma treatment. Chest 2006;130(1 Suppl):65S-72S.

13. Axelsson M, Lotvall J. Recent educational interventions for improvement of asthma medication adherence. Asia Pac Allergy 2012;2:67-75.

14. Costello RW, Foster JM, Grigg J, Eakin MN, Canonica W, Yunus F, et al. The seven stages of man: the role of developmental stage on medication adherence in respiratory diseases. J Allergy Clin Immunol Pract 2016;4:813-20.

15. Lareau SC, Yawn BP. Improving adherence with inhaler therapy in COPD. Int J Chron Obstruct Pulmon Dis 2010;5:401-6.

16. Lindsay JT, Heaney LG. Nonadherence in difficult asthma - facts, myths, and a time to act. Patient Prefer Adherence 2013;7:329-36.

17. van Boven JF, Trappenburg JC, van der Molen T, Chavannes NH. Towards tailored and targeted adherence assessment to optimise asthma management. NPJ Prim Care Respir Med 2015;25:15046.

18. Hill DA, Grundmeier RW, Ram G, Spergel JM. The epidemiologic characteristics of healthcare provider-diagnosed eczema, asthma, allergic rhinitis, and 
food allergy in children: a retrospective cohort study. BMC Pediatr 2016;16: 133.

19. Jones RC, Price D, Ryan D, Sims EJ, von Ziegenweidt J, Mascarenhas L, et al Opportunities to diagnose chronic obstructive pulmonary disease in routine care in the UK: a retrospective study of a clinical cohort. Lancet Respir Med 2014;2: 267-76.

20. Lavorini F, Mannini C, Chellini E, Fontana GA. Optimising inhaled pharmacotherapy for elderly patients with chronic obstructive pulmonary disease: the importance of delivery devices. Drugs Aging 2016;33:461-73.

21. Levy ML, Hardwell A, McKnight E, Holmes J. Asthma patients' inability to use a pressurised metered-dose inhaler (pMDI) correctly correlates with poor asthma control as defined by the Global Initiative for Asthma (GINA) strategy: a retrospective analysis. Prim Care Respir J 2013;22:406-11.

22. Global Initiative for Asthma. 2017 GINA Report: global strategy for asthma management and prevention. Available from: http://ginasthma.org. Accessed May 7, 2017.

23. Williams LK, Peterson EL, Wells K, Ahmedani BK, Kumar R, Burchard EG, et al. Quantifying the proportion of severe asthma exacerbations attributable to inhaled corticosteroid nonadherence. J Allergy Clin Immunol 2011;128: 1185-91.e2

24. Melani AS, Bonavia M, Cilenti V, Cinti C, Lodi M, Martucci P, et al. Inhaler mishandling remains common in real life and is associated with reduced disease control. Respir Med 2011;105:930-8.

25. Molimard M, Raherison C, Lignot S, Balestra A, Lamarque S, Chartier A, et al Chronic obstructive pulmonary disease exacerbation and inhaler device handling: real-life assessment of 2935 patients. Eur Respir J 2017;49:1601794. https://doi.org/10.1183/13993003.01794-2016.

26. van Boven JF, Chavannes NH, van der Molen T, Rutten-van Mölken MP, Postma MJ, Vegter S. Clinical and economic impact of nonadherence in COPD a systematic review. Respir Med 2014;108:103-13.

27. Hoskins G, McCowan C, Neville RG, Thomas GE, Smith B, Silverman S. Risk factors and costs associated with an asthma attack. Thorax 2000:55:19-24.

28. Andersson F, Borg S, Jansson SA, Jonsson AC, Ericsson A, Prütz C, et al. The costs of exacerbations in chronic obstructive pulmonary disease (COPD). Respir Med 2002;96:700-8

29. Lewis A, Torvinen S, Dekhuijzen PN, Chrystyn H, Watson AT, Blackney M, et al. The economic burden of asthma and chronic obstructive pulmonary disease and the impact of poor inhalation technique with commonly prescribed dry powder inhalers in three European countries. BMC Health Serv Res 2016;16: 251.

30. Fink JB, Rubin BK. Problems with inhaler use: a call for improved clinician and patient education. Respir Care 2005;50:1360-74. discussion 74-5.

31. Engelkes M, Janssens HM, de Jongste JC, Sturkenboom MC, Verhamme KM. Medication adherence and the risk of severe asthma exacerbations: a systematic review. Eur Respir J 2015:45:396-407.

32. Morton RW, Elphick HE, Rigby AS, Daw WJ, King DA, Smith LJ, et al STAAR: a randomised controlled trial of electronic adherence monitoring with reminder alarms and feedback to improve clinical outcomes for children with asthma. Thorax 2017;72:347-54.

33. Price D, Harrow B, Small M, Pike J, Higgins V. Establishing the relationship of inhaler satisfaction, treatment adherence, and patient outcomes: a prospective, real-world, cross-sectional survey of US adult asthma patients and physicians. World Allergy Organ J 2015;8:26

34. Zafari Z, Lynd LD, FitzGerald JM, Sadatsafavi M. Economic and health effect of full adherence to controller therapy in adults with uncontrolled asthma: a simulation study. J Allergy Clin Immunol 2014;134:908-15.e3.

35. Chrystyn H, Small M, Milligan G, Higgins V, Gil EG, Estruch J. Impact of patients' satisfaction with their inhalers on treatment compliance and health status in COPD. Respir Med 2014;108:358-65.

36. van Boven JF, Tommelein E, Boussery K, Mehuys E, Vegter S, Brusselle GG, et al. Improving inhaler adherence in patients with chronic obstructive pulmonary disease: a cost-effectiveness analysis. Respir Res 2014;15:66.

37. Toy EL, Beaulieu NU, McHale JM, Welland TR, Plauschinat CA, Swensen A et al. Treatment of COPD: relationships between daily dosing frequency, adherence, resource use, and costs. Respir Med 2011;105:435-41.

38. Vestbo J, Anderson JA, Calverley PM, Celli B, Ferguson GT, Jenkins C, et al Adherence to inhaled therapy, mortality and hospital admission in COPD Thorax 2009;64:939-43.

39. Lavorini F, Corrigan CJ, Barnes PJ, Dekhuijzen PR, Levy ML, Pedersen S, et al Retail sales of inhalation devices in European countries: so much for a global policy. Respir Med 2011;105:1099-103.
40. Lavorini F, Usmani OS. Correct inhalation technique is critical in achieving good asthma control. Prim Care Respir J 2013:22:385-6.

41. Braido F, Lavorini F, Blasi F, Baiardini I, Canonica GW. Switching treatments in COPD: implications for costs and treatment adherence. Int J Chron Obstruct Pulmon Dis 2015;10:2601-8.

42. Bosnic-Anticevich S, Chrystyn H, Costello RW, Dolovich MB, Fletcher MJ, Lavorini $\mathrm{F}$, et al. The use of multiple respiratory inhalers requiring different inhalation techniques has an adverse effect on COPD outcomes. Int J Chron Obstruct Pulmon Dis 2016;12:59-71.

43. Sanchis J, Gich I, Pedersen S. Systematic review of errors in inhaler use: Has patient technique improved over time? Chest 2016;150:394-406.

44. Dekhuijzen PN, Vincken W, Virchow JC, Roche N, Agusti A, Lavorini F, et al. Prescription of inhalers in asthma and COPD: towards a rational, rapid and effective approach. Respir Med 2013;107:1817-21.

45. Haughney J, Price D, Barnes NC, Virchow JC, Roche N, Chrystyn H. Choosing inhaler devices for people with asthma: current knowledge and outstanding research needs. Respir Med 2010;104:1237-45.

46. Small M, Anderson P, Vickers A, Kay S, Fermer S. Importance of inhalerdevice satisfaction in asthma treatment: real-world observations of physicianobserved compliance and clinical/patient-reported outcomes. Adv Ther 2011; 28:202-12.

47. Unni E, Shiyanbola OO. Clustering medication adherence behavior based on beliefs in medicines and illness perceptions in patients taking asthma maintenance medications. Curr Med Res Opin 2016;32:113-21.

48. van Boven JFM, Lavorini F, Dekhuijzen PNR, Blasi F, Price DB, Viegi G. Urging Europe to put non-adherence to inhaled respiratory medication higher on the policy agenda: a report from the First European Congress on Adherence to Therapy. Eur Respir J 2017;49:1700076. https://doi.org/10.1183/13993003. 00076-2017.

49. Leiva-Fernandez J, Leiva-Fernandez F, Garcia-Ruiz A, Prados-Torres D, Barnestein-Fonseca P. Efficacy of a multifactorial intervention on therapeutic adherence in patients with chronic obstructive pulmonary disease (COPD): a randomized controlled trial. BMC Pulm Med 2014;14:70.

50. Tommelein E, Mehuys E, Van Hees T, Adriaens E, Van Bortel L, Christiaens T, et al. Effectiveness of pharmaceutical care for patients with chronic obstructive pulmonary disease (PHARMACOP): a randomized controlled trial. Br J Clin Pharmacol 2014;77:756-66.

51. van Boven JF, Ryan D, Eakin MN, Canonica GW, Barot A, Foster JM, Respiratory Effectiveness Group. Enhancing respiratory medication adherence: the role of health care professionals and cost-effectiveness considerations. J Allergy Clin Immunol Pract 2016;4:835-46.

52. Hanania NA, Wittman R, Kesten S, Chapman KR. Medical personnel's knowledge of and ability to use inhaling devices: metered-dose inhalers, spacing chambers, and breath-actuated dry powder inhalers. Chest 1994;105:111-6.

53. Plaza V, Sanchis J, Roura P, Molina J, Calle M, Quirce S, et al. Physicians' knowledge of inhaler devices and inhalation techniques remains poor in Spain. J Aerosol Med Pulm Drug Deliv 2012;25:16-22.

54. Wilson SR, Strub P, Buist AS, Knowles SB, Lavori PW, Lapidus J, et al. Better Outcomes of Asthma Treatment Study Group. Shared treatment decision making improves adherence and outcomes in poorly controlled asthma. Am J Respir Crit Care Med 2010;181:566-77.

55. Hall RL, Willgoss T, Humphrey LJ, Kongsø JH. The effect of medical device dose-memory functions on patients' adherence to treatment, confidence, and disease self-management. Patient Prefer Adherence 2014;8:775-88.

56. Craven VE, Morton RW, Spencer S, Devadson SG, Everard ML. Electronic monitoring and reminding devices for improving adherence to inhaled therapy in patients with asthma (protocol). Cochrane Database Syst Rev 2015;3: CD011554. https://doi.org/10.1002/14651858.CD011554.

57. Sulaiman I, Cushen B, Greene G, Seheult J, Seow D, Rawat F, et al. Objective assessment of adherence to inhalers by patients with chronic obstructive pulmonary disease. Am J Respir Crit Care Med 2017;195:1333-43.

58. Plaza V, Fernandez-Rodriguez C, Melero C, Cosío BG, Entrenas LM, de Llano LP, et al. Validation of the "Test of the Adherence to Inhalers" (TAI) for asthma and COPD patients. J Aerosol Med Pulm Drug Deliv 2016;29: 142-52.

59. Elliott RA, Barber N, Clifford S, Horne R, Hartley E. The cost effectiveness of a telephone-based pharmacy advisory service to improve adherence to newly prescribed medicines. Pharm World Sci 2008;30:17-23.

60. Petrie KJ, Perry K, Broadbent E, Weinman J. A text message programme designed to modify patients' illness and treatment beliefs improves self-reported adherence to asthma preventer medication. Br J Health Psychol 2012;17:74-84. 